\title{
Layout effect of two Autonomous Underwater Vehicles on the hydrodynamics performances
}

\author{
MUSTAPHA HELMAOUI ${ }^{*},{ }^{1}$, FETHI SAIDI ${ }^{1}$, HOUSSEM LAIDOUDI ${ }^{1}$, AICHA SEDINI ${ }^{1}$, \\ ABDELLAH GHENAIM \\ ${ }^{1}$ Aero-Hydrodynamic Naval Laboratory, Maritime Department, \\ University of Science and Technology M-B, Oran, Algeria \\ ${ }^{2}$ Fluid Mechanics Team-ICUBE-UMR 7357, INSA Strasbourg, FRANCE. \\ helmaouisara@yahoo.fr
}

\begin{abstract}
Three-dimensional computational fluid dynamics (CFD) is used for the design optimization of the layout of an autonomous underwater vehicles (AUV) containing three torpedo-shaped hulls. The AUV layout is defined by two parameters a and $\mathrm{b}$ present the stance following $\mathrm{YY}$ and $\mathrm{XX}$ respectively. several simulations are carried on the AUV with different positions of the torpedo in order to define the optimal layout which designates the minimum drag. the numerical results approve that the variation in the drag coefficient of the AUV is the to the interaction of the flow rate and the pressure change between the both hulls. in addition, an optimal layout for the minimum AUV drag with two torpedoes is found which provides a drag reduce of about $11.4 \%$ lower than a single UV with a single torpedo.
\end{abstract}

Key-Words: Drag reduction-hydrodynamic coefficients- layout effect- underwater vehicle- CFD.

Received: December 22, 2019. Revised: February 24, 2020. Accepted: March 7, 2020. Published: March 16, 2020.

\section{Nomenclature}

L ATIN

AUV $=$ Autonomous Underwater Vehicle

$\mathbf{F}_{\mathbf{d}}=$ drag force $(\mathrm{N})$

$\mathbf{P}=$ pressure $(\mathrm{Pa})$

$\mathbf{P}_{\infty}=$ atmospheric pressure $(\mathrm{Pa})$

$\boldsymbol{\tau}_{\boldsymbol{\omega}}=$ shear stress $(\mathrm{Pa})$

$\boldsymbol{U}=$ flow Velocity $\left(\mathrm{m} \mathrm{s}^{-1}\right)$

$\mathrm{A}_{\mathrm{f}}=$ torpedo surface $\left(\mathrm{m}^{2}\right)$

$\mathrm{C}_{\mathrm{d}}=$ drag coefficient

$\mathrm{C}_{\mathrm{d} 1}=$ drag coefficient of leader torpedo

$\mathrm{C}_{\mathrm{d} 2}=$ drag coefficient of follower torpedo

$\mathrm{C}_{\mathrm{dt}}=$ total drag coefficient of AUV (both torpedos)

$\mathrm{C}_{\mathrm{f}}=$ friction coefficient

$\mathrm{C}_{\mathrm{p}}=$ Pressure coefficient

$\mathrm{R}_{\mathrm{e}}=$ Reynolds number

$\mathrm{C}_{\mathrm{p}}=$ Pressure coefficient

$\mathrm{R}_{\mathrm{e}}=$ Reynolds number

\section{GREEK}

$\mu=$ Dynamic viscosity $\left(\mathrm{kg} \mathrm{m}^{-1} \mathrm{~s}^{-1}\right)$

$\rho=$ Density $\left(\mathrm{kg} \mathrm{m}^{-3}\right)$

\section{Introduction}

Today, underwater robots are an integral part of scientific equipment to explore the seas and oceans. Many examples have shown that ROVs (Remotely Operating Vehicles) are used in many fields and this, for various applications such as inspection, cartography or even bathymetry. These vehicles are confronted to broad scientific problems such as: decision autonomy, navigation coupled with the problem of positioning, energy autonomy and without forgetting the difficult piloting of intervention ROVs, researchers have started to think about the realisation of the intervention Autonomous Underwater Vehicle (AUV). Without the need for the tether management system and dynamic position system. These AUVs could be operated from vessels of opportunity reducing considerably the cost. In this context, a significant number of AUVs able to perform missions of the order of weeks and months have been requested. This requires that the AUV design be optimal as possible, which claim a careful analysis of the hydrodynamic performance of the AUV structure. Several experimental and numerical studies are available in the literature to analyse the hydrodynamic parameters around AUV [1,2]. These studies are supported by experimental work. Jagadees et al. 2009 [3] observed using experimental analysis that the hydrodynamic force coefficients are very sensitive to the depth of immersion and the speed of the AUV. Saeidinezhad et al. 2015 [4], carried out an experimental analysis of the effect of the Reynolds number on the pitch and on the drag coefficient of a submersible vehicle model. Javadi et al. 2015 [5] performed an 
experimental investigation of the effect of bow profiles on the resistance of the AUV in a towing tank at different Froude numbers and studied the variability of the friction drag as a function of the Froude number. In 2016, T. Gao et al [6], performed an analysis based on the drag force of several geometries experimentally tested in a hull basin. Shahrieel et al., 2013[7], have experimentally demonstrated the implementation of the design of an AUV as a test bed platform for various researches on underwater technologies, in particular small underwater robots' ladder.

In addition, the use of the computational fluid dynamics (CFD) in the AUV development is concerning the optimization based on the resistance of the hull. In this context, several researches have been carried out on AUV in order to improve its hydrodynamic performance. A. A. Mishra, 2014 [8] developed a comparison between real-time scenario data and simulated data from an autonomous underwater vehicle (AUV) using the proposed models. Regarding to advancement resistance, $\mathrm{T}$. Hwan Joung et al., 2012 [9], realized a numerical study to optimize the shape of an autonomous underwater vehicle with propeller. The same method was used by Philips et al. 2007 [10] to determine the strength of the existing AUV hull, of three different shapes of the tail. On the other hand, D. R. Blidberg, 2001 [11], studied the modeling and control of an autonomous underwater vehicle using a software. Sedini et al, 2019 [12], carried out a geometrical optimization based on the hydrodynamic coefficients, this study was reinforced by an analysis carried out on coefficients of added masses and the damping force in order to help to understand the behavior of acceleration AUV at sea.

With the improvement of computing facilities, the design of AUVs is increasingly becoming a methodology based on simulation. CFD (Computational Fluid Dynamics) simulations greatly reduce dependence on traditional large-scale experiments on complex test benches. The use of such computer-controlled simulations allows rapid and inexpensive testing of complex design iterations that could be costly and time-consuming to reproduce and test in real life. It also allows aggregation of data with greater precision and statistics that are not evident in conventional experiments.

Several achievements combine two or even more torpedo-shaped hulls to realise an AUV, in order to avoid the autonomy problem. This article presents an optimisation process for an AUV, which contains three torpedo-shaped hulls. The AUV layout is defined by two parameters $\mathrm{a}$ and $\mathrm{b}$ present the displacement following YY and XX respectively. Three-dimensional CFD simulations are carried out to determine the drag of each case, and the optimal arrangement giving a minimum drag.

\section{Methodology}

The AUV design of the system to be studied consists of three torpedo-shaped hulls, two of which are positioned in a horizontal plane above the third torpedo (Fig 1).

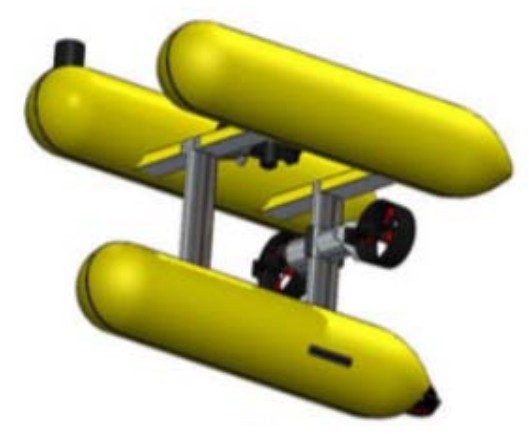

Fig 1.AUV design

The studied AUV body is an axisymmetric form, the study is therefore focused on two torpedo-shape in a vertical projection (Fig 2).

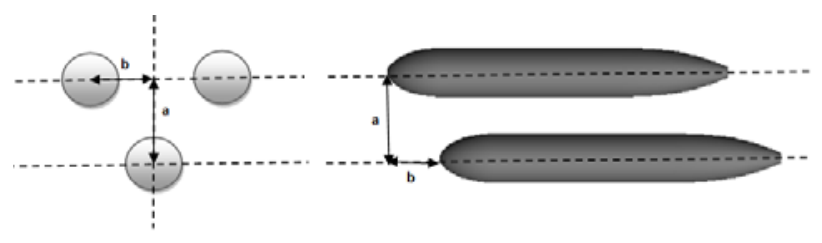

Fig 2. Model configuration

The distances $a$ and $b$ present the displacement following yy and $\mathrm{xx}$ respectively.

Three cases are treated, and each of them undergoes two 3D CFD simulations in order to find the drag of every case. Next, we define the optimal layout which designates the minimum drag. Table 1 shows the values of a and $b$ for each simulation. 
Table 1: $\mathbf{a}$ and $\mathbf{b}$ values.

\begin{tabular}{l|llllll}
\hline CASE & $I$ & \multicolumn{1}{l}{ II } & \multicolumn{3}{l}{ III } \\
\hline Simulations & 1 & 2 & 1 & 2 & 1 & 2 \\
$\mathrm{a}(\mathrm{m})$ & 0 & 0 & 0,275 & 0,375 & 0,275 & 0,375 \\
$\mathrm{~b}(\mathrm{~m})$ & 1,5 & 1,75 & 0 & 0 & 1,5 & 1,75 \\
\hline
\end{tabular}

\subsection{Geometry and computational domain}

\begin{tabular}{cccccc}
$\mathrm{D}(\mathrm{m})$ & $\mathrm{L}(\mathrm{m})$ & $\mathrm{e}(\mathrm{m})$ & $\mathrm{h}(\mathrm{m})$ & $\mathrm{c}(\mathrm{m})$ & $\theta\left({ }^{\circ}\right)$ \\
\hline & & & & & \\
0.2 & 1.3 & 0.2 & 0.7 & 0.4 & 30 \\
\hline
\end{tabular}

The torpedo geometries were generated by 1 and 2 Myring 1976, equations. The torpedo is composed by a nose at the upstream and a tail at the downstream shown in figure 3. Its geometric characteristics are given in table 2.

$$
r_{1}(x)=\frac{1}{2} D\left[1-\left(\frac{x-e}{e}\right)^{\frac{1}{n}}\right]
$$

The nose sections are determined from equations (1), Where $x$ is the position along the rotation axis, $r_{1}$ is the radius at a specific $x, e$ is the length of the nose, $D$ is the diameter of torpedo

$$
\begin{aligned}
& r_{2}(x)=\frac{1}{2} D-\left[\frac{3 d}{2 c^{2}}-\frac{\tan (\theta)}{c}\right](x-(\text { 先 }+ \\
& h))^{2}+\left[\frac{d}{c^{3}}-\frac{\tan (\theta)}{c^{2}}\right](x-(e+h))^{3}
\end{aligned}
$$

The tail sections are determined from equations (2), where $h$ is the length between nose and tail, $c$ the length of nose and e circular cone has an angle $\theta$.

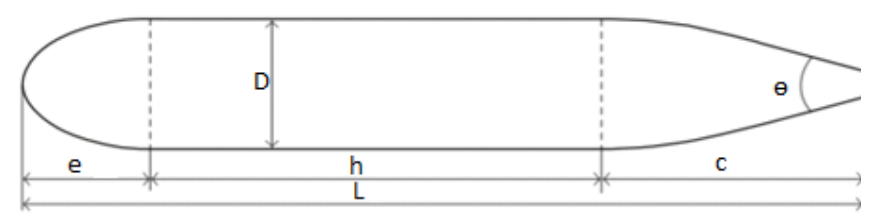

Fig3. AUV parameters of Myring Equation

The $\mathrm{d}$ is determined after the torpedo length truncation

\section{parameters}

Tableau 2: Torpido Dimension

As it is shown in figure 4, a rectangular computational domain is chosen to avoid the flow return effect. It extends up to $4 \mathrm{~L}$ upstream of the leading edge and 4L downstream of the trailing edge and respectively $16 \mathrm{D}$ and $14 \mathrm{D}$ as the height and width of the domain.

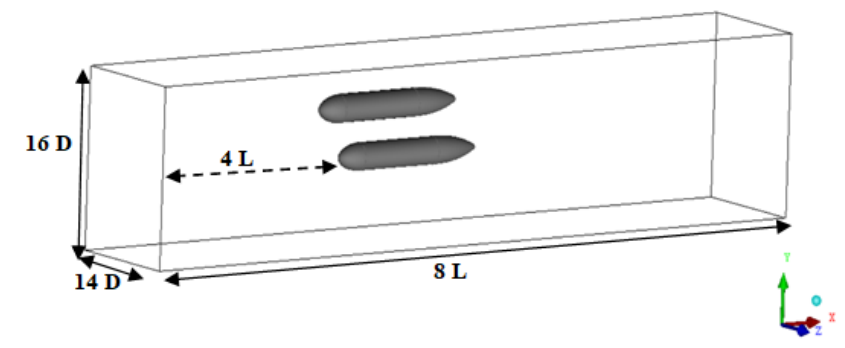

Fig 4. Computational domain

\subsection{Mesh assessment}

Two different tetrahedral meshes were generated using the ICEM software (Fig 5). A prism option with five (05) layers was used in the both grid in order to get a good result at the boundary layer. The elements number of the both meshes used is presented in the Table 3

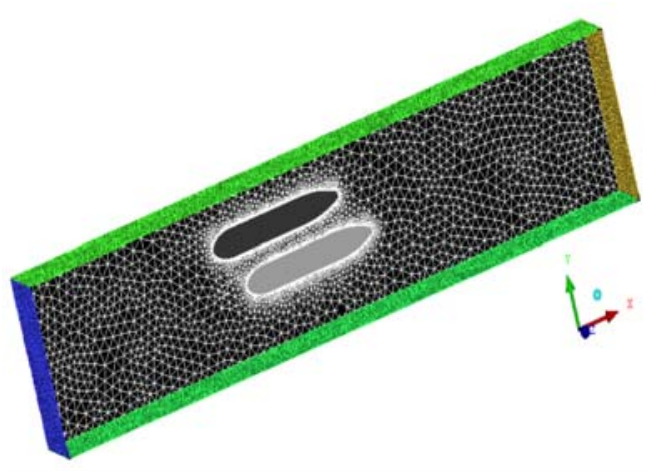



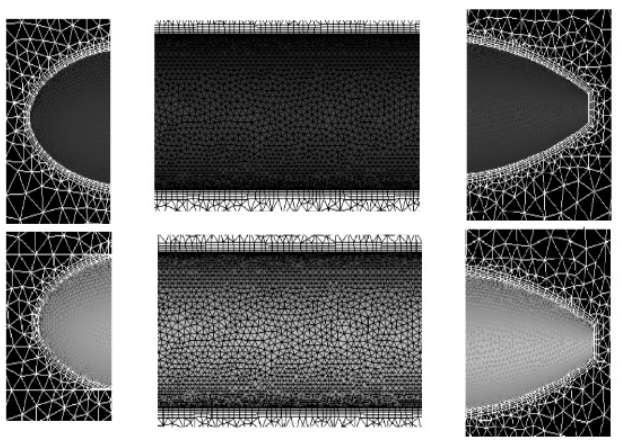

Fig 5.Computational grid

Tableau 3: Meshes elements numbers

\begin{tabular}{ll}
\hline Tetra mesh & $\begin{array}{l}\text { Elements } \\
\text { numbers }\end{array}$ \\
\hline Refined & 1638949 \\
\hline Coarse & 1046789 \\
\hline
\end{tabular}

Figure 6 shows a comparison of the two results of the evolution of the pressure coefficient around the one torpedo. A disturbance is noted in the depression part (Z1) for the coarse mesh; however, a stabilization was noted for the refined mesh.

According to the result of the $\mathrm{Cp}$, the refined mesh gives more precision in the boundary layer part.

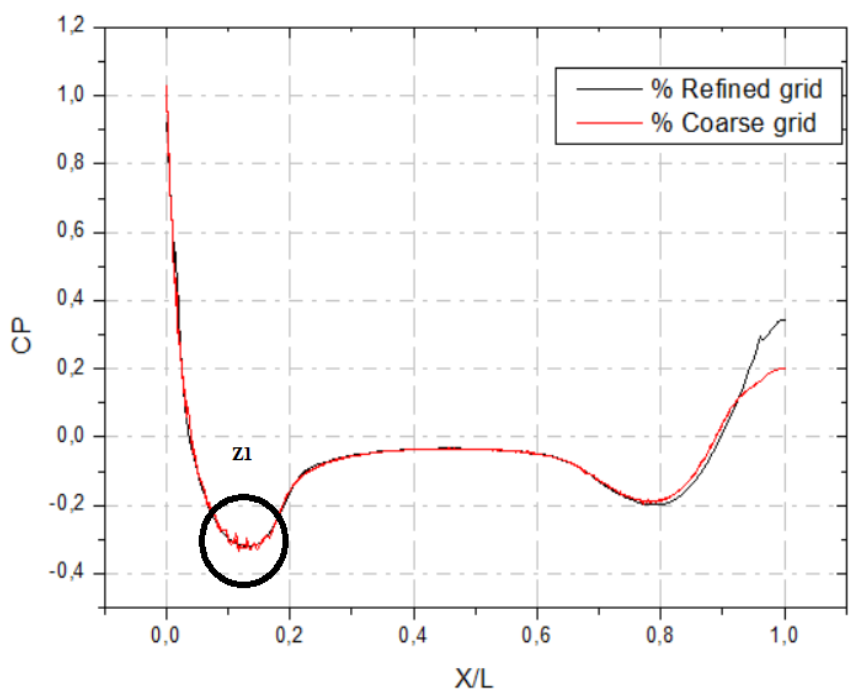

Fig6. Pressure coefficient of both meshes (refined and coarse)

\subsection{Turbulence model and Boundary conditions}

As it was demonstrated by Jagadeesh et al in 2005, the $\mathrm{k} \varepsilon$ model is the best for predicting the hydrodynamic coefficients and the treatment of the boundary layer while being in good agreement with experimental data.

The turbulence model $\mathrm{k} \varepsilon$ is a two-equation model which uses transport equations to determine the balance of the kinetic energy of the fluctuations $(\mathrm{k})$ and the energy dissipation (ع) [Z. Laffane et al. 2019].

The boundary conditions must be applied to all the regions at the ends (external and internal) of the computational domain $\mathrm{R}_{\mathrm{e}}=3.210^{6}, \boldsymbol{\mu}=1.19$ $10^{-6} \mathrm{~kg} \mathrm{~m}^{-1} \mathrm{~s}^{-1}, \mathbf{0}=998 \mathrm{~kg} \mathrm{~m}^{-3}$ and the outlet pressure is

$\mathbf{P}=0 \mathrm{~Pa}$

\subsection{Hydrodynamics coefficients}

The objective of this study is to find an optimal layout of torpedoes in order to have a minimum drag for the AUV. For that, we focused on the following normalized equations: 


\section{$\checkmark$ Drag coefficient:}

This coefficient belongs to the family of aerodynamic coefficients. It is a dimensionless number that is used to quantify the drag or resistance of AUV in water.

$$
\begin{aligned}
& \mathrm{C}_{\mathrm{d}}=\frac{\mathbf{F}_{\mathbf{d}}}{\frac{1}{2} \rho U^{2} \cdot \mathrm{A}_{\mathrm{f}}} \\
& \checkmark \quad \text { Pressure coefficient: }
\end{aligned}
$$

The coefficient $\mathrm{Cp}$ is an adimensional number which describes the relative pressure across a flow field. It is defined by the following formula:

$$
\begin{aligned}
\mathrm{C}_{\mathrm{p}} & =\frac{\mathbf{p}-\mathbf{p}_{\infty}}{\frac{1}{2} \rho U^{2}} \\
\checkmark & \text { Friction coefficient: }
\end{aligned}
$$

The coefficient of friction is the ratio between the sliding force and the holding force, exerted by the contact between AUV and water.

$$
\mathrm{C}_{\mathrm{f}}=\frac{\boldsymbol{\tau}_{\boldsymbol{\omega}}}{\frac{1}{2} \rho U^{2}}
$$

\section{Results and discussions}

\subsection{Model evaluation}

The concept of the experimental study of White, N.M., $1977\left(\mathrm{R}_{\mathrm{e}}=2.3010^{7}\right)$ is transferred in order to evaluate the CFD model used in this investigation

The table 4 shows the model evaluation by comparing the predicted drag coefficient with experimental results. Drag values for a single AUV model (one torpedo) at Reynold number of $2,3.10^{7}$ was calculated through CFD code and compared to experimental works. According to this result we note that the $C_{d}$ obtained during this simulation is in good agreement with the experimental study of White, N.M., 1977.
Table 4 Drag coefficient validation

CD CD

EXP White, N.M, 1977 PRESENT STUDY

$\mathrm{R}_{\mathrm{e}}=2.3010^{7} \quad 0.00123 \pm 0.000314 \quad 0.00132$

\subsection{CFD optimisation}

The optimisation is performed for the Reynold number $\mathrm{R}_{\mathrm{e}}=3.210^{7}$

\section{$\checkmark$ Layout $a$ and $b$ effect on the drag coefficient}

Table 5 present the drag coefficient $\left(\mathrm{C}_{\mathrm{d}}\right)$ variation according to each layout $\mathrm{a}$ and $\mathrm{b}$.

The overall drag generated by the movement of AUV in water includes, the front shape drags due to the direct pressure of water on the front of the AUV, and the friction drag due to the sliding of the AUV. water on the surface of the AUV. Of all this, the overall drag behaves in proportionality with the speed of the flow around the AUV.

We can distinguish several specific zones: at the nose of the two torpedoes, a significant zone of boundary layer along the torpedoes, wider zones, probably turbulent, in the spaces between torpedoes, at the tail of the train, and in the rear wake of the torpedoes .

The $C_{d}$ values obtained by numerical simulations clearly show that the modification of $a$ and $b$ affect the flow around the UV.

According to the table, the horizontal distance a has an inverse influence on the drag coefficient $\mathrm{C}_{\mathrm{d}}$ for each AUV, and regarding the vertical distance $b$ has a proportional influence on this coefficient $\left(\mathrm{C}_{\mathrm{d} 1}, \mathrm{C}_{\mathrm{d} 2}\right.$ and $\left.\mathrm{C}_{\mathrm{dt}}\right)$. The combination of parameters $\mathrm{a}$ and $\mathrm{b}$ has the effect of increasing $\mathrm{C}_{\mathrm{d} 1}$, decreasing $\mathrm{C}_{\mathrm{d} 2}$ and $\mathrm{C}_{\mathrm{dt}}$.

The minimum $\mathrm{C}_{\mathrm{dt}}$ noted during these simulations is that of case II, simulation one (1) is around $10^{-3}$. 
Table 5 Predicted drag coefficients

\begin{tabular}{|c|c|c|c|c|}
\hline & & $\mathrm{C}_{\mathrm{d} 1}(-)$ & $\mathrm{C}_{\mathrm{d} 2}(-)$ & $C_{d A I}(-)$ \\
\hline $\mathrm{a}(\mathrm{m})$ & $b=0$ & & & \\
\hline 0.275 & & 0.0125201 & 0.0186183 & 0.0311384 \\
\hline 0.375 & & 0.0120498 & 0.00982492 & 0.02187472 \\
\hline $\mathrm{b}(\mathrm{m})$ & $a=0$ & & & \\
\hline 1.5 & & 0.00593186 & 0.000932474 & 0.006864334 \\
\hline 1.75 & & 0.0103603 & 0.00223936 & 0.01259966 \\
\hline $\mathrm{a}(\mathrm{m})$ & $\mathrm{b}(\mathrm{m})$ & & & \\
\hline$a=0.275$ & $5 \mathrm{~b}=1.5$ & 0.00973717 & 0.00268382 & 0.01242099 \\
\hline$a=0.375$ & $5 \mathrm{~b}=1.75$ & 0.0107621 & 0.00135073 & 0.01211283 \\
\hline
\end{tabular}

\section{$\checkmark \quad$ Layout $a$ and $b$ effect on the pressure coefficient}

In order to confirm the accuracy of the optimization results, the pressure coefficients $\mathrm{Cp}$ according to AUV length (Both torpedo) are visualized in Figure 7.

The pressure coefficient behaves identically to that mentioned in the literature of flows around obstacles; it is maximum on the leading edge and decreases sharply along the curvature of the nose to reach a minimum value. It stabilizes just after in the middle of the AUV and increases slightly along the tail. We notice that there is no separation of the boundary layer therefore the coefficient $\mathrm{C}_{\mathrm{p}}$ in this study is relatively independent of the speed of the flow and we conclude that it is related only to the AUV shapes.

- For case I, we notice for $\mathrm{a}=0.275$, the difference between $\mathrm{C}_{\mathrm{P} 1}$ and $\mathrm{C}_{\mathrm{P} 2}$ is larger than that for $\mathrm{a}=0.375$. This difference is due to the short distance between the two AUVS, which causes a large speed gradient.

- For case II, we notice that the value of CP2 for $b=1.75$ is greater than that for $b=1.25$ at the edge point 'attack. The difference between $\mathrm{C}_{\mathrm{P} 1}$ and $\mathrm{C}_{\mathrm{P} 2}$ is noted particularly at the front part (the nose) of the AUV, this corresponds to the vertical distance $b$ separating the two AUVs.

- For case III, the pressure coefficient behaves as in the previous case. We note that by combining the parameters $a$ and $b$ such that $\mathrm{a}=0.275$ with $\mathrm{b}=1.5$ and $\mathrm{a}=$ 0.375 with $b=1.75$, the values of $\mathrm{C}_{\mathrm{P} 2}$ increase more than the other cases. according to these results of $\mathrm{C}_{\mathrm{p}}$, the best configuration is that of $a=0, b=1.5$ (case II)
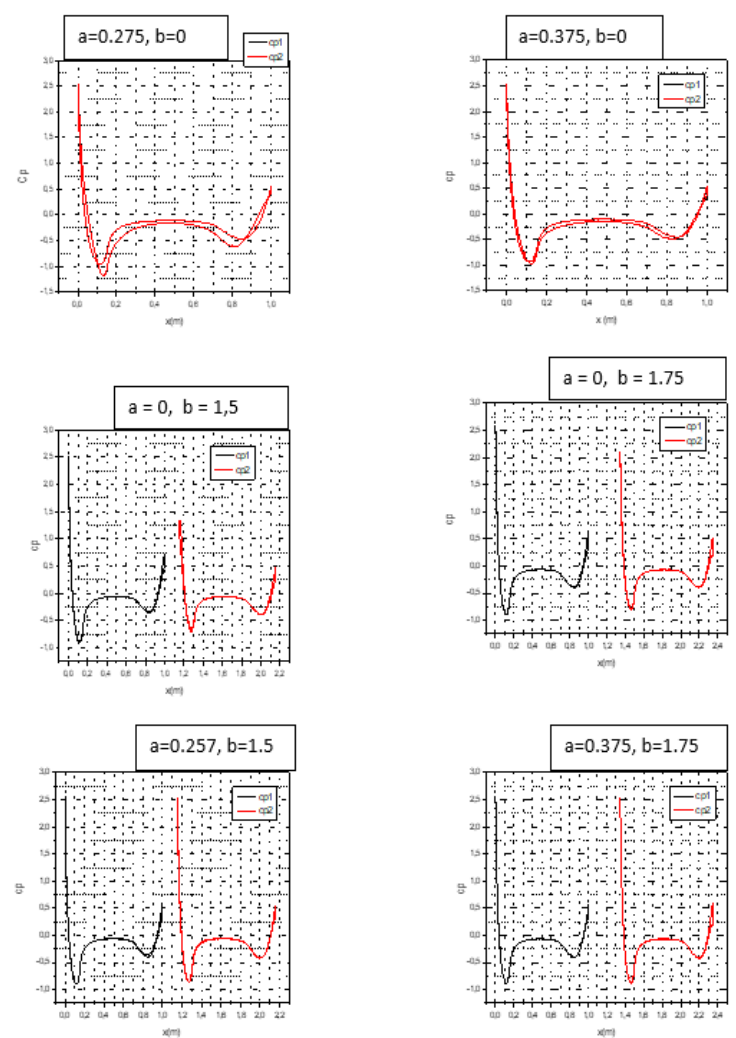

Figure 7: Pressure coefficient $\mathrm{Cp}$ variation for different configurations

Layout $a$ and $b$ effect on the friction coefficient

Figure 8 shows the variation of the friction coefficient $\mathrm{Cf}$ according to the layout $\mathrm{a}$ and $\mathrm{b}$.

In this study, the AUV used is non-profiled, so this friction term is Insignificant in the face of the action of pressure. The order of magnitude of the friction coefficients is $10^{-2}$, to be compared to the pressure coefficients.

The $\mathrm{C}_{\mathrm{f}}$ is inversely proportional to the $\mathrm{C}_{\mathrm{p}}$ i.e. minimum on the leading-edge point. It increases suddenly along the curvature of the nose to reach a maximum value (acceleration of the fluid) and stabilizes just after in the middle of the AUV after it decreases along the tail

The coefficient of friction Cf increase suddenly and reaches its maximum over the AUV nose in 
both cases $(\mathrm{a}=0.275, \mathrm{a}=0.375)$ due to the velocity gradient inflation. It decreases just after and takes a relatively stable shape in the middle of the AUV, to decrease again along the trailing edge. However, an inversely proportional relation is noted between the $\mathrm{C}_{\mathrm{f}}$ and the parameter $\mathrm{a}$. In the second case where the $\mathrm{a}=0$, $\mathrm{b}=1,5$ and 1,75 respectively, the $\mathrm{C}_{\mathrm{f}}$ evolution increase as in the previous cases over the nose surface and reaches a maximum. In the midst of the AUV, the $\mathrm{C}_{\mathrm{f}}$ stabilizes relatively, and its value drop at the trailing edge. For the last case, the combination of the changes of the both layouts $a$ and $b$ at the same time gives the same of $\mathrm{C}_{\mathrm{f}}$ behavior and practically the same values as the second case.
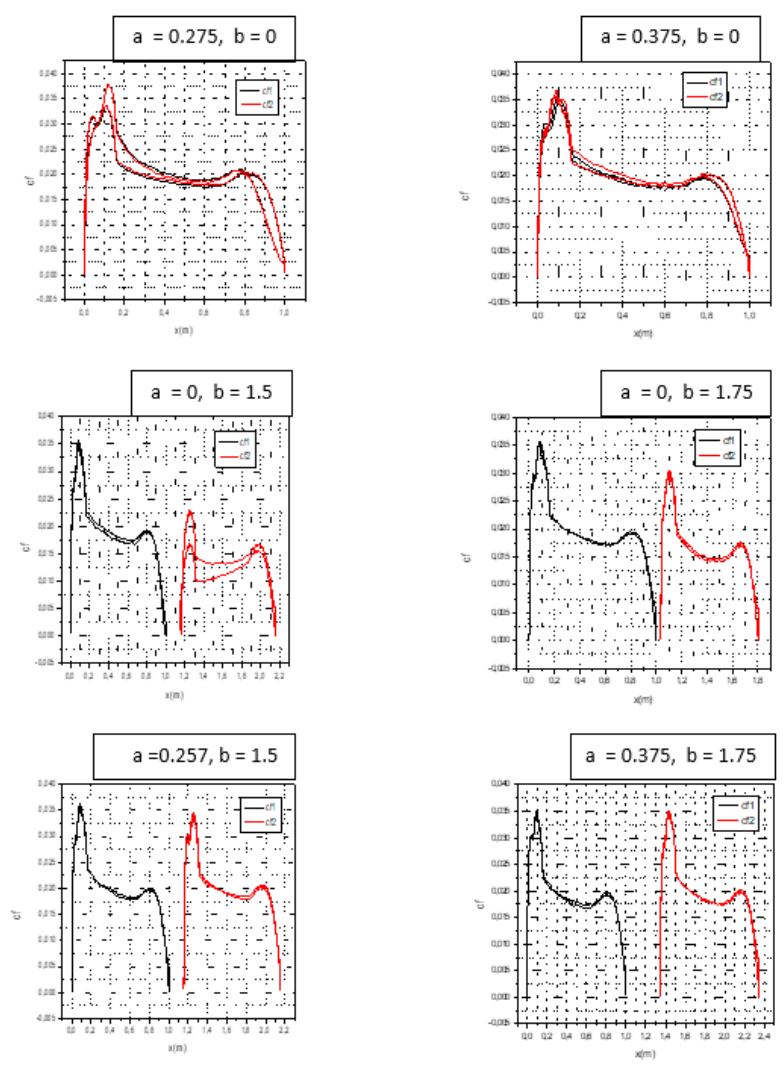

Figure 8: Friction coefficient $\mathrm{C}_{\mathrm{f}}$ variation for different configurations

\section{Conclusion}

Total AUV drag influences uptime and range of underwater vehicles. In this study, the CFD is used to find the optimal configuration based on the minimum drag of an AUV composed of identical three torpedo. The important conclusions of this study are as follows:

- The CFD results show that the drag coefficients of the AUV are determined by the relative position of the both hulls. The variation in the drag coefficient of the AUV is the result of the interaction of the flow rate and the pressure change between the both hulls.

- The optimal parameters for the minimum AUV drag with two torpedoes are determined for the layout $a=0.00$ and $b=$ 1.5 , where the second torpedo is in the tandem region which provides for a drag of about $11.4 \%$ lower than an AUV with a single torpedo. This gain is marked by $\mathrm{Z} 2$ in Figure 9, it is explained by the increase in pressure in the wake of the first torpedo (AUV with 2 torpedoes), this overpressure gives a positive thrust upstream.
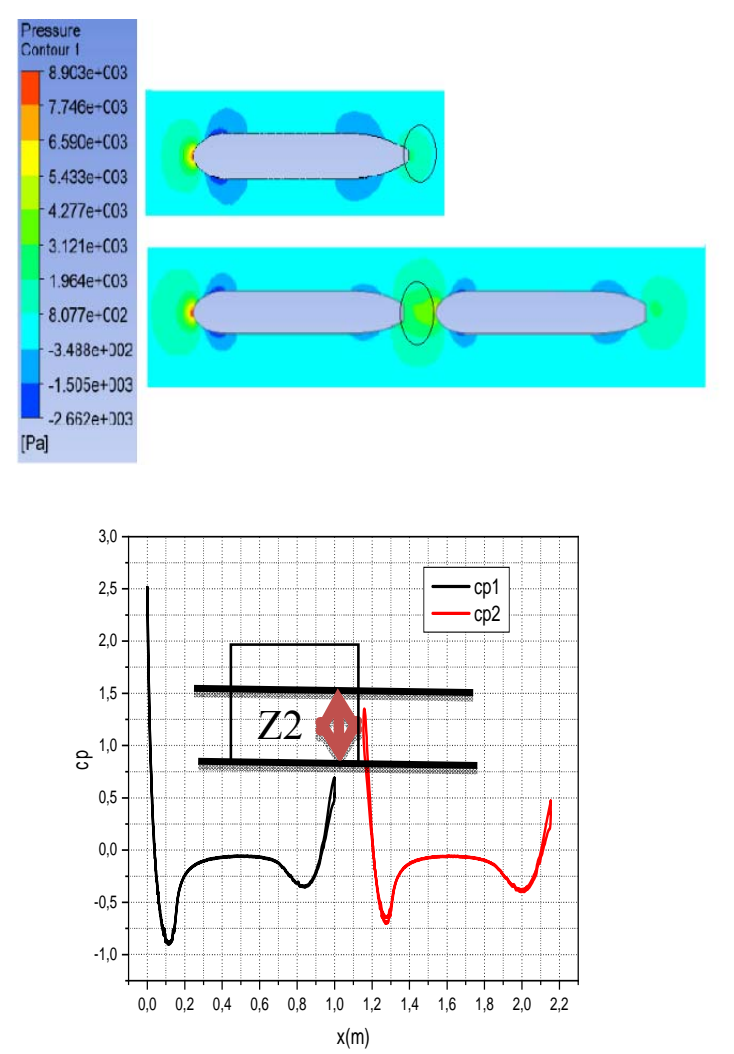

Figure 9 : Pressure Contours around the single torpedo and the optimal layout for two torpedoes 


\section{References}

[1] A. A. Mishra. (August 2014). The art and science in modeling the pressure-velocity interactions. $\mathrm{PhD}$ Thesis, Texas A\&M University, College Station, TX.

[2] Aicha Sedini, Fethi Saidi, Abdellah Mokhtari, Zakarya Laffane. (2019). Optimization and Analysis of the Hydrodynamic Coefficients for an Underwater Vehicle (UV). WSEAS Transactions on Fluid Mechanics, , Vol 14, Art. \#17, 154-161

[3] A. Phillips, M. Furlong, SR. (2007). The use of computational fluid dynamics to assess the hull resistance of concept autonomous underwater vehicles. Turnock, of Ocean Engineering, 1-6.

[4] A. Saeidinezhad, AA. Dehghan, MD. Manshadi. (2015). Experimental investigation of hydrodynamic characteristics of a submersible vehicle model with a nonaxisymmetric nose in pitch maneuver. Ocean engineering. Vol. 100, 26-34.

[5] DF. Myring. (1976). A theoretical study of body drag in subcritical axisymmetric flow. The Aeronautical Quarterly. Vol. 27, n. 3, 186194.

[6] D. R. Blidberg. (2001) The development of autonomous underwater vehicles (auv); a brief summary. IEEE, Icra, Vol. 4, 1.

[7] M. Javadi, M. D. Manshadi, S. Kheradmand, M. Moonesun. (2015). Experimental investigation of the effect of bow profiles on resistance of an underwater vehicle in free surface motion. Journal of Marine Science and Application 14 (1), 53-60.

[8] M. M. Amiri, S. H. Sphaier, M. A. Vitola, P. T. Esperana. (2019). Urans investigation of the interaction between the free surface and a shallowly submerged underwater vehicle at steady drift. Applied Ocean Research, 84, 192205.

[9] Mohd Shahrieel Mohd Aras, Shahrum Shah Abdullah, , Azhan Ab. Rahman, and Muhammad Azhar Abd Aziz. (2013). Thruster Modelling for Underwater Vehicle Using System Identification Method. International Journal of Advanced Robotic Systems, Vol. 10, 252

[10] NM. White. (1977). A comparison between a simple drag formula and experimental drag data for bodies of revolution. David W Taylor Naval Ship Research and Development Center Bethesda MD.

[11] P. Jagadeesh, K. Murali, CG. (2009). Idichandy, Experimental investigation of hydrodynamic force coefficients over AUV hull form, Ocean engineering. Vol. 36, n. 1, 113-118

[12] P. Jagadeesh, K. Murali. (2005). Application of low-Re turbulence models for flow simulations past underwater vehicle hull forms. Journal of Naval Architecture and Marine Engineering. Vol. 2, n. 1, 41-54.

[13] T. Gao,Y. Wang, Y. Pang, J. Cao. (2016). Hull shape optimization for autonomous underwater vehicles using CFD. Engineering applications of computational fluid mechanics. Vol. 20, n. 1, 599-607.

[14] T. H. Joung, K. Sammut, F. He, and S.-K. Lee. (2012). Shape optimization of an autonomous underwater vehicle with a ducted propeller using computational fluid dynamics analysis. International Journal of Naval Architecture and Ocean Engineering, Vol. 4, no. 1, 44-56.

[15] Z. Laffane, F. Saidi, B. Hamoudi, Y. Boualia, A. Sedini. (2019). Passive Blowing on NACA 0012 Profile with Attached Gurney Flap. International Review of Mechanical Engineering, Vol. 13, N. 7, 427-437

[16] Z. Leong, D. Ranmuthugala, A. Forrest, J. Duffy, et al., Numerical investigation of the hydrodynamic interaction between two underwater bodies in relative motion, Applied Ocean Research 51 (2015) 14-24. 